\title{
Recent Advances in Enzyme Based Glucose Biosensors for Biomedical Applications
}

\author{
Dipali Rakesh Mohan Bagal-Kestwal* and Been Huang Chiang* \\ Institute of Food Science and Technology, National Taiwan University, Taiwan
}

Submission: April 24, 2017; Published: May 04, 2017

${ }^{*}$ Corresponding author: Dipali Rakesh Mohan Bagal-Kestwal, Institute of Food Science and Technology, National Taiwan University, No.1, Roosevelt Road, section 4, Taipei, Taiwan, ROC, Taiwan, Email: dipalik18@ntu.edu.tw

Been Huang Chiang, Institute of Food Science and Technology, National Taiwan University, No.1, Roosevelt Road, section 4, Taipei, Taiwan, R0C, Taiwan, Tel: 886233664119; Fax: 886223620849; Email: bhchiang@ntu.edu.tw

\section{Mini Review}

Busy lifestyle has significant influence on health. Unhealthy living style not only leads to unbalanced nutrition but also increasesoccurrence of metabolic diseases, particularly diabetes. Therefore, there is a constant need of monitoring blood glycemic level using biosensor [1]. In recent decades, biosensing has proven to be an innovative technique in several fields, such as environment and biomedical applications [2].

A litmus-paper-like test that utilized glucose oxidase (GOx), peroxidase (POx), and a chromogen to quantify glucose in urine was developed by the Miles-Ames Laboratories in 1957 [3]. Since urine glucose level is fluid intake dependent and suffersfrom accuracy and reliability problems, more accurate blood glucose test-strip was developed and accepted by consumer market. Because of advances in technology, teststrip was then replaced by glucometer for personal use. First revolutionary glucose electrode was proposed by Clark \& Lyons [4]. And then immobilized GOxbased sensor was commenced by Updike \& Hicks [5]. Since then amperometric, potentiometric, and impedimetric or conductometric glucose biosensors based on the GOx were developed and employed for biomedical applications.

Enzyme-based biosensors for glucose monitoring can be used off-line, in vivo and on-line [6]. The off-line glucose estimation is usually carried out using biosensor-based analytical equipment and samples from different sources can be tested. In vivo biosensors are implanted and extracellular changes of glucose concentration are detected continuously [2]. On-line glucose biosensor devices are integrated with a sampling device and can be used to detect glucose content of a liquid during biochemical processing [6].

Enzymatic detection methods always rely on biological activity of free or native enzyme. Most of the enzymes can only keep their activity under some limited condition sand the enzyme instability often limits their usesinsensor device. Various immobilization strategies can be employed to improve the storage and thermal stability as well as the specificity of enzymes. Improved sensitivity, selectivity and specificity with reusability of the enzymes can be achieved by immobilization methods such as entrapment, cross-linking, physical adsorption, covalent or ionic bonding, and encapsulation. Owing to the mesoporous network based matrix, biopolymers, synthetic polymers and one, two and three dimensional nanostructures are useful platform to immobilize glucose oxidase and other enzymes for glucose biosensing [7,8]

Biosensors can be classified into three generations according to the method of attachment of the biorecognition molecule/bioreceptor to the transducer [9]. The first generation biosensors were mostly oxygen sensors where bioreceptor is physically entrapped in the vicinity of the sensor separated by a barrier such as dialysis membrane. In the second generation biosensor architecture, the individual components remain essentially distinct and use mediators for communication. In the third generation biosensors thebioreceptorbecomes an integral part of the base sensing element by coupling technique. Different enzymes such as GOx, POx, hexokinase, glucokinase and glucose dehydrogenases (GDHs) have been used for fabricating glucose sensors [3]. GOx is a dimeric enzyme which catalyzes the conversion of $\beta$-d-glucose to d-glucono-1, 5-lactone, it is the first enzyme used in bi/tri-enzyme glucose sensing systems which depend upon two or three step detection. GOx, catalase, invertase, beta-glucanaseand peroxidase are used in conjunction with active fluorescent, visible light chromophore,nanodot or nanostructure for optical sensors.GOx with flavin adenosine dinucleotide (FAD) cofactor is electrochemically active, thus the mediators and other enzymes can be eliminated to construct the third generation sensors. This not only reduces the cost of the probe system but also allows direct electron transfer between 
enzyme and electrode,and results in short response time. Another enzyme used for glucose quantification is hexokinase or glucokinase (subset of hexokinase). Although hexokinase can beused independently,most frequently it couples with glucose6-phosphate dehydrogenase (G6PDH). Four different types of GDHare often used in glucose sensing: glucose-1-dehydrogenase (G1DH), quinoproteinglucose dehydrogenase (Q-GDH),G6PDH, andFAD-glucose dehydrogenase (FAD-GDH). However, GDHs are $\mathrm{pH}$ and temperature sensitive and not glucose specific therefore not routinely used in glucose sensing assays. Quinoprotein glucose dehydrogenases, also known as pyrroloquinoline quinine glucose dehydrogenases (PQQ-GDH), are a class of enzymes that utilize PQQ or ubiquinone as a redox cofactor for the oxidation of glucose [3]. Their substrate turnover is equivalent to that of GOx and oxygen independent, allowing the applications of these enzymes not only in biofuel and glucometers but also in food industry. On other hand, FAD-GDH is mechanistically and structurally similar to GOx and can be used with wide range of mediators. However, GOx needs oxygen to regenerate its cofactor while FAD-GDH not. These different enzyme-based glucose detection systems are developed using transducers like optic

(absorbance/reflection/surface plasmon/polarization/ luminescence/refraction/dispersion/fluorescence), electrochemical (potential/conductance/impedance/ coulometric/field effective transistor) and acoustic/gravimetric.

Sensor generation is also matured with growing nanotechnology. State-of-the-art glucose biosensors are improved by incorporating nanomaterials such as carbon nanotubes, gold nanoparticles, silver nanoparticles, graphene, electrospun nanofibers, and quantum dots [10]. Enzyme-based sensor system become more useful when integrated with nanostrcutures or nanomaterials. This integration not only improves signal output but also faster response with high biocatalytic activity $[3,7]$. Nanomaterials also allow fabrication of nanoscale biosensors with more facile administration ofcontinuous glucose monitoring when implanted. However, more detailed research on nanomaterials and nanofabrication techniques for improvement of sensor architecture is still needed. There are limitations on clinical use of nanosensors for continuous glucose monitoring as these devices suffer from fouling, decreased sensor life due to immune response and management cost. Despite extensive research on enzyme-free glucose sensors, there is still no commercial product. Biosensors for continues glucose monitoring will undoubtedly focus on accuracy, reliability, cost and durability.

\section{References}

1. Song Y, Luo Y, Zhu C, Li H, Du D, Lin Y (2017) Recent advances in electrochemical biosensors based on graphene two-dimensional nanomaterials. Biosens Bioelectron 76: 195-212.

2. Rocchitta G, Spanu A, Babudieri S, Latte G, Madeddu G, et al. (2016) Enzyme biosensors for biomedical applications: strategies for safeguarding analytical performances in biological fluids. Sensors 16 (780): $1-21$.

3. Masashige Taguchi BS, Ptitsyn A, Eric S, McLamore ES, et al. (2014 ) Nanomaterial-mediated biosensors for monitoring glucose. J Diabetes Sci Technol 8(2): 403-411.

4. Clark Jr L, Lyons C (1962) Electrode systems for continuous monitoring in cardiovascular surgery. Ann NY AcadSci 102: 29-45.

5. Updike S J, Hicks GP (1967) The Enzyme Electrode. Nature 214: 986988.

6. Castillo J, Gáspár S, Leth S, Niculescu M, Mortari A, Bontidean I, et al. (2004) Biosensors for life quality: Design, development and applications. Sens Actuators B Chem 102(20): 179-194.

7. Bagal-Kestwal DR, Kestwal RM and Chiang BH (2015) Fenugreek hydrogel-agarose composite entrapped gold nanoparticles for acetylcholinesterase based biosensor for carbamates detection. Anal ChimActa 886: 143-150.

8. Bagal DS, Karve MS (2006) Entrapment of plant invertase within novel composite of agarose- guar gum biopolymer membrane. Anal ChimActa 555: 316-321.

9. Grieshaber D, MacKenzie R, Janos Vörös J, Reimhult E (2008) Electrochemical Biosensors - Sensor Principles and Architectures. Sensors 8(3): 1400-1458.

10. Bagal-Kestwal DR, Kestwal RM and Chiang BH (2015) Invertasenanogold clusters decorated onion membranes for fluorescence-based sucrose sensor. J Nanobiotechnol 13 (30): 1-11.

\section{Your next submission with Juniper Publishers will reach you the below assets}

- Quality Editorial service

- Swift Peer Review

- Reprints availability

- E-prints Service

- Manuscript Podcast for convenient understanding

- Global attainment for your research

- Manuscript accessibility in different formats

( Pdf, E-pub, Full Text, Audio)

- Unceasing customer service

Track the below URL for one-step submission https://juniperpublishers.com/online-submission.php 